Case Report

\title{
Synovial Chondromatosis of the Ankle Joint: Clinical, Radiological, and Intraoperative Findings
}

\author{
Sedeek Mohamed Sedeek, ${ }^{1}$ Q. Choudry, ${ }^{1}$ and S. Garg ${ }^{2}$ \\ ${ }^{1}$ Department of Orthopaedics, East Lancashire Hospitals NHS Trust, Royal Blackburn Hospital, Blackburn BB2 3HH, UK \\ ${ }^{2}$ Department of Orthopaedics, Royal Lancaster Infirmary, Lancaster LA1 4RP, UK \\ Correspondence should be addressed to Sedeek Mohamed Sedeek; sedeeko2000@hotmail.com
}

Received 10 February 2015; Accepted 18 May 2015

Academic Editor: Akio Sakamoto

Copyright (c) 2015 Sedeek Mohamed Sedeek et al. This is an open access article distributed under the Creative Commons Attribution License, which permits unrestricted use, distribution, and reproduction in any medium, provided the original work is properly cited.

\begin{abstract}
Synovial chondromatosis, also termed synovial osteochondromatosis, is a rare benign disorder characterized by the presence of cartilaginous nodules in the synovium of the joints, tendon sheaths, and bursae. It most commonly involves large joints, such as the knee, hip, and shoulder, but its presence in smaller joints has also been reported. Nevertheless, ankle involvement is unusual. The diagnosis is commonly made following a thorough history, clinical, physical, and radiographic examination. We report a case of a young patient with primary synovial chondromatosis of the ankle joint and present the clinical, radiographic, and intraoperative findings.
\end{abstract}

\section{Introduction}

Synovial chondromatosis is a rare benign condition characterized by the formation of intra-articular cartilaginous nodules in the synovium of joints [1]. These nodules can detach and become loose bodies within the joint and may undergo secondary calcification and proliferation [2]. The etiology of synovial chondromatosis is not recognized. Histologically, synovial cells undergo metaplasia to chondrocytes, producing multiple cartilage nodules [3]. Synovial chondromatosis is most common in men in the third to fourth decade of life, often occurring in large joints, including the knee and hip, with smaller joints being less frequently involved $[4,5]$. Patients commonly present with pain, swelling, and limited motion. Additionally, effusion, diffuse tenderness, and crepitus can be found on clinical examination [2].

Synovial chondromatosis originating from the ankle is an exceedingly rare condition $[6,7]$. Herein, we present a case of synovial chondromatosis of the ankle joint treated by surgical excision and its outcome.

\section{Case Report}

A 21-year-old male patient presented to our clinic with 18month history of pain in his left ankle which had deteriorated over the last year. He complained of stiffness, crepitation, and a catching sensation in the ankle; he felt as if he was "walking on pebbles." Physical examination revealed a mildly tender swelling on the anterolateral aspect of the ankle joint. The patient was able to dorsiflex the ankle up to $10^{\circ}$, while plantar flexion was possible up to $20^{\circ}$. Anterior positive impingement was noted, while no instability was detected. There were no vascular or neurological abnormalities in the ankle and laboratory studies were within the normal range.

Plain radiographs of the left ankle revealed a large speculated calcified mass of loose bodies emerging from the anterior aspect of the ankle (Figure 1). As there was no history of direct ankle trauma or systemic inflammatory disease, primary synovial chondromatosis was strongly suspected. The patient underwent arthrotomy, surgical excision of the intraarticular bodies (Figure 2). Over 50 intra-articular bodies were retrieved, all of which were homogenous in appearance and ranged from 3 to $9 \mathrm{~mm}$ in size (Figure 3). The joint was irrigated by copious amounts of normal saline. There was no synovial proliferation or thickening; hence, a synovectomy was not performed. Postoperatively, the patient was allowed to perform partial weight bearing for 2 weeks. Histological examination confirmed the diagnosis of primary synovial chondromatosis. Postoperative radiographs showed no loose 


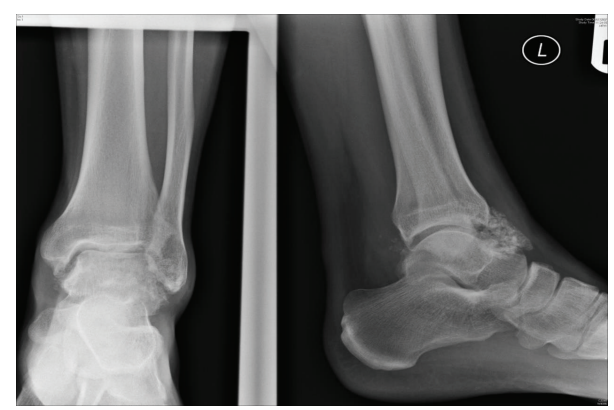

FIGURE 1: Preoperative radiographs showing a large speculated mass of calcified loose bodies.

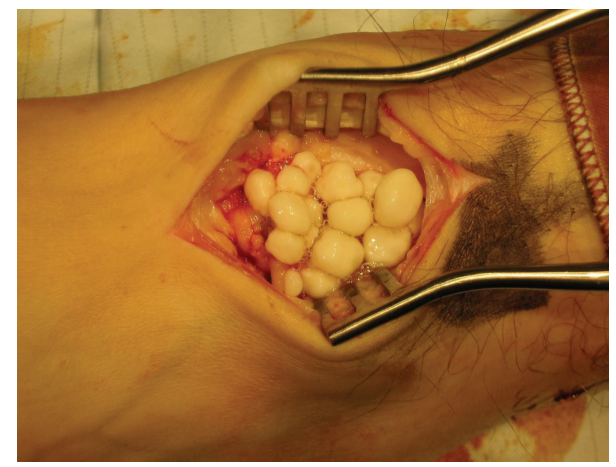

FIGURE 2: Arthrotomy of the ankle showing loose intra-articular bodies.

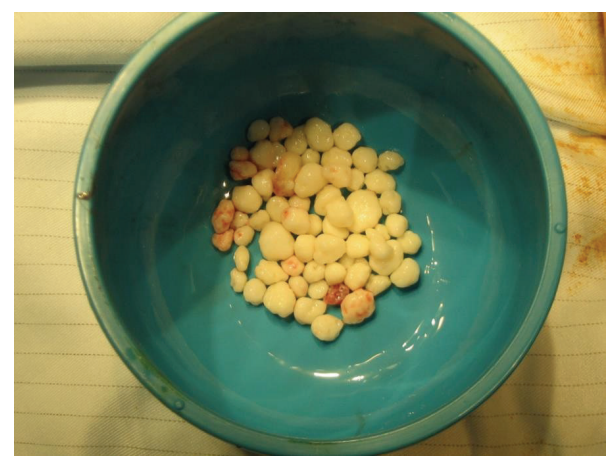

FIGURE 3: More than 40 retrieved loose bodies which were homogenous in appearance.

bodies in the ankle joint. At one-year follow-up, the patient was pain-free with a full range of ankle joint motion and had returned to his previous daily activity levels.

\section{Discussion}

Synovial chondromatosis is a rare benign synovial lesion characterized by multiple pearl-like intra- and extra-articular osteochondral loose bodies $[1,8]$. Involvement is typically monoarticular, with large joints being most frequently affected. The knee joint is involved in 60 to $70 \%$ of cases and the shoulder, elbow, and hip are the next most frequently involved joints [9]. Synovial chondromatosis of the foot and ankle is a very rare condition. A review of the literature shows a limited number of reported cases involving the foot and ankle $[10,11]$.

It is broadly concurred that the exact etiology of synovial chondromatosis is unknown. Milgram et al. classified the disease process into three distinct stages $[12,13]$. During the first stage, the synovial lining undergoes cartilaginous metaplasia. In the second stage, the nodules begin to detach from the synovium and appear as loose bodies; during this stage the patient becomes symptomatic. In the third stage, multiple loose bodies can be observed within the joint cavity with no visible intrasynovial bodies, indicating that activation of the synovium has subsided. The loose bodies also have a tendency to unite and calcify $[12,13]$.

Clinically, patients with synovial chondromatosis usually present with pain, swelling, stiffness, and/or a detectable mass, and most of them have a long clinical history before an accurate diagnosis is made [14]. There has been recent interest in the diagnosis of these cases due to a potential malignant degeneration. In 1998, Davis et al. reported a 5\% relative risk for malignant degeneration in primary chondromatosis cases [15]. Imaging plays a crucial role in the diagnosis of synovial chondromatosis, with calcifications being present in standard radiographic examination in 70 to $95 \%$ of cases. Multiple calcified bodies, typically smooth, round, and of variable size, found within the joint capsule, are findings with diagnostic significance [16]. Nevertheless, radiographs may only reveal an increase in soft tissue density around the affected joint [7]. Thus, in cases where plain radiography cannot demonstrate calcification or ossification, magnetic resonance imaging is particularly useful [6].

The goal for the treatment of synovial chondromatosis is to remove the loose bodies, improve pain symptoms, regain movement in the joint, and limit the development of early osteoarthritis [7]. The treatment of choice is either open or arthroscopic surgical excision. Synovectomy is usually performed when active synovitis is present, usually stage 1 or stage 2. Most patients present in the late stage when active synovitis is no longer present; hence, a synovectomy is not required [17]. Recurrence occurs in 3\% to $23 \%$ of cases, and it is thought to be after synovectomy with active synovium remaining or the presence of the stimulus which caused the metaplasia $[5,13,18]$. Our patient underwent open arthrotomy and loose body removal and was without recurrence at last follow-up. Open arthrotomy was the technique of choice to ensure complete removal of the heavy mass of calcified loose bodies observed in preoperative radiographic studies.

\section{Conclusions}

We report a case of primary diffuse synovial chondromatosis of the ankle. This unusual, distinctive benign synovial neoplasm presents readily recognizable clinical, radiographic, and pathological features. Primary synovial chondromatosis is adequately treated by loose body resection either arthroscopically or through open surgery. Prognosis is excellent. 


\section{Conflict of Interests}

The authors declare that there is no conflict of interests regarding the publication of this paper.

\section{References}

[1] R. Hocking and J. Negrine, "Primary synovial chondromatosis of the subtalar joint affecting two brothers," Foot and Ankle International, vol. 24, no. 11, pp. 865-867, 2003.

[2] M. A. Adelani, R. M. Wupperman, and G. E. Holt, "Benign synovial disorders," Journal of the American Academy of Orthopaedic Surgeons, vol. 16, no. 5, pp. 268-275, 2008.

[3] E. Buess and B. Friedrich, "Synovial chondromatosis of the glenohumeral joint: a rare condition," Archives of Orthopaedic and Trauma Surgery, vol. 121, no. 1-2, pp. 109-111, 2001.

[4] C.-Y. Chen, A. C.-Y. Chen, Y.-H. Chang, T.-S. Fu, and M. S. Lee, "Synovial chondromatosis of the hip: management with arthroscope-assisted synovectomy and removal of loose bodies: report of two cases," Chang Gung Medical Journal, vol. 26, no. 3, pp. 208-214, 2003.

[5] T. Shpitzer, A. Ganel, and S. Engelberg, "Surgery for synovial chondromatosis. 26 cases followed up for 6 years," Acta Orthopaedica Scandinavica, vol. 61, no. 6, pp. 567-569, 1990.

[6] A. Blandino, L. Salvi, G. Chirico et al., "Synovial osteochondromatosis of the ankle: MR findings," Clinical Imaging, vol. 16, no. 1, pp. 34-36, 1992.

[7] M. N. Doral, A. Uzumcugil, M. Bozkurt et al., "Arthroscopic treatment of synovial chondromatosis of the ankle," Journal of Foot and Ankle Surgery, vol. 46, no. 3, pp. 192-195, 2007.

[8] W. Kistler, "Synovial chondromatosis of the knee joint: a rarity during childhood," European Journal of Pediatric Surgery, vol. 1, no. 4, pp. 237-239, 1991.

[9] A. K. Walling and S. I. Gasser, "Soft-tissue and bone tumors about the foot and ankle," Clinics in Sports Medicine, vol. 13, no. 4, pp. 909-938, 1994.

[10] D. D. Galat, D. B. Ackerman, D. Spoon, N. S. Turner, and T. C. Shives, "Synovial chondromatosis of the foot and ankle," Foot and Ankle International, vol. 29, no. 3, pp. 312-317, 2008.

[11] F. Young-In Lee, F. J. Hornicek, H. M. Dick, and H. J. Mankin, "Synovial chondromatosis of the foot," Clinical Orthopaedics and Related Research, no. 423, pp. 186-190, 2004.

[12] J. W. Milgram and R. G. Addison, "Synovial osteochondromatosis of the knee. Chondromatous recurrence with possible chondrosarcomatous degeneration," The Journal of Bone \& Joint Surgery-American Volume, vol. 58, no. 2, pp. 264-266, 1976.

[13] J. W. Milgram, "Synovial osteochondromatosis: a histopathological study of thirty cases," The Journal of Bone \& Joint Surgery Series A, vol. 59, no. 6, pp. 792-801, 1977.

[14] P. I. Wuisman, R. J. Noorda, and P. C. Jutte, "Chondrosarcoma secondary to synovial chondromatosis. Report of two cases and a review of the literature," Archives of Orthopaedic and Trauma Surgery, vol. 116, no. 5, pp. 307-311, 1997.

[15] R. I. Davis, A. Hamilton, and J. D. Biggart, "Primary synovial chondromatosis: a clinicopathologic review and assessment of malignant potential," Human Pathology, vol. 29, no. 7, pp. 683688, 1998.

[16] K. Wong, D. Sallomi, D. L. Janzen, P. L. Munk, J. X. O’Connell, and M. J. Lee, "Monoarticular synovial lesions: radiologic pictorial essay with pathologic illustration," Clinical Radiology, vol. 54, no. 5, pp. 273-284, 1999.
[17] D. P. Dworak and M. H. McGuire, "Primary synovial osteochondromatosis in the ankle: a case report," The American Journal of Orthopedics, vol. 40, no. 5, pp. E96-E98, 2011.

[18] H. Maurice, M. Crone, and I. Watt, "Synovial chondromatosis," The Journal of Bone \& Joint Surgery -British Volume, vol. 70, no. 5, pp. 807-811, 1988. 


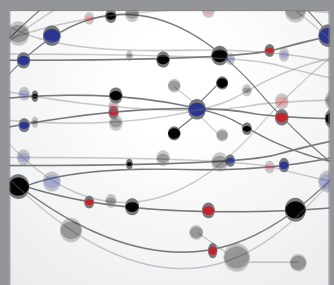

The Scientific World Journal
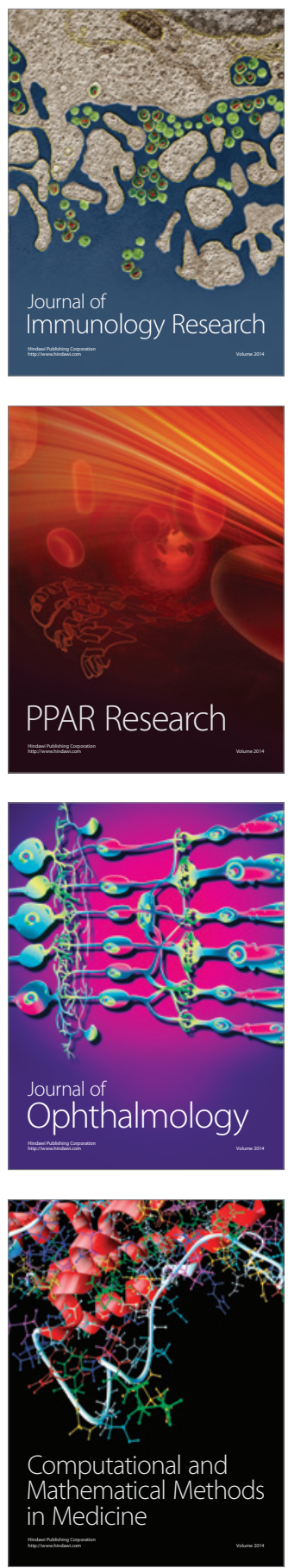

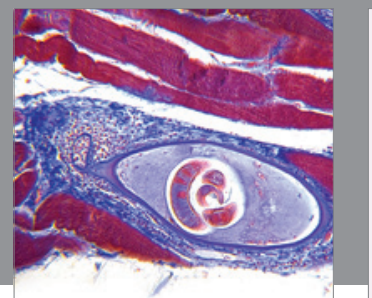

Gastroenterology

Research and Practice
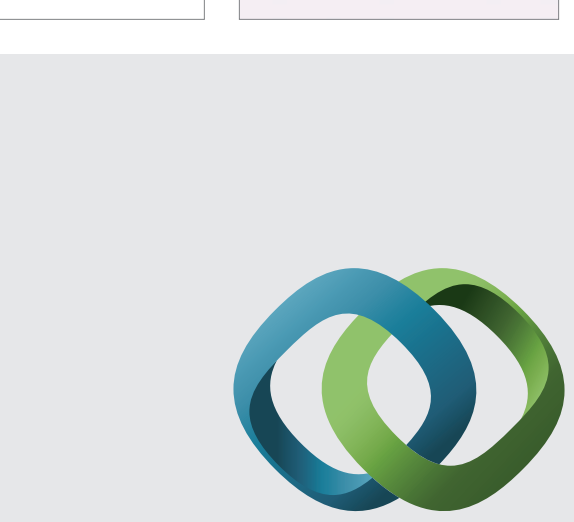

\section{Hindawi}

Submit your manuscripts at

http://www.hindawi.com
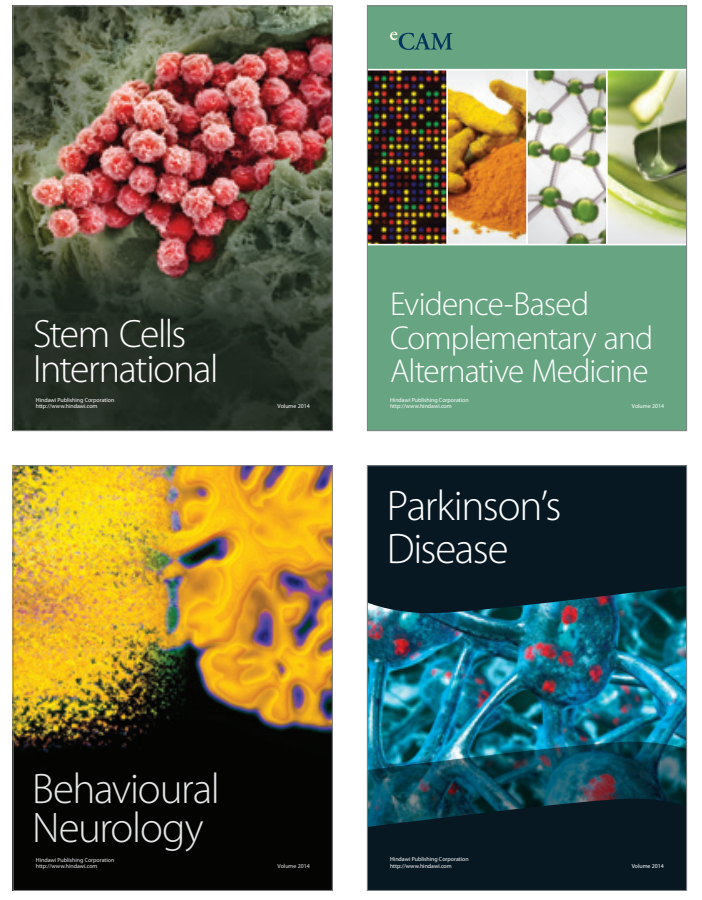
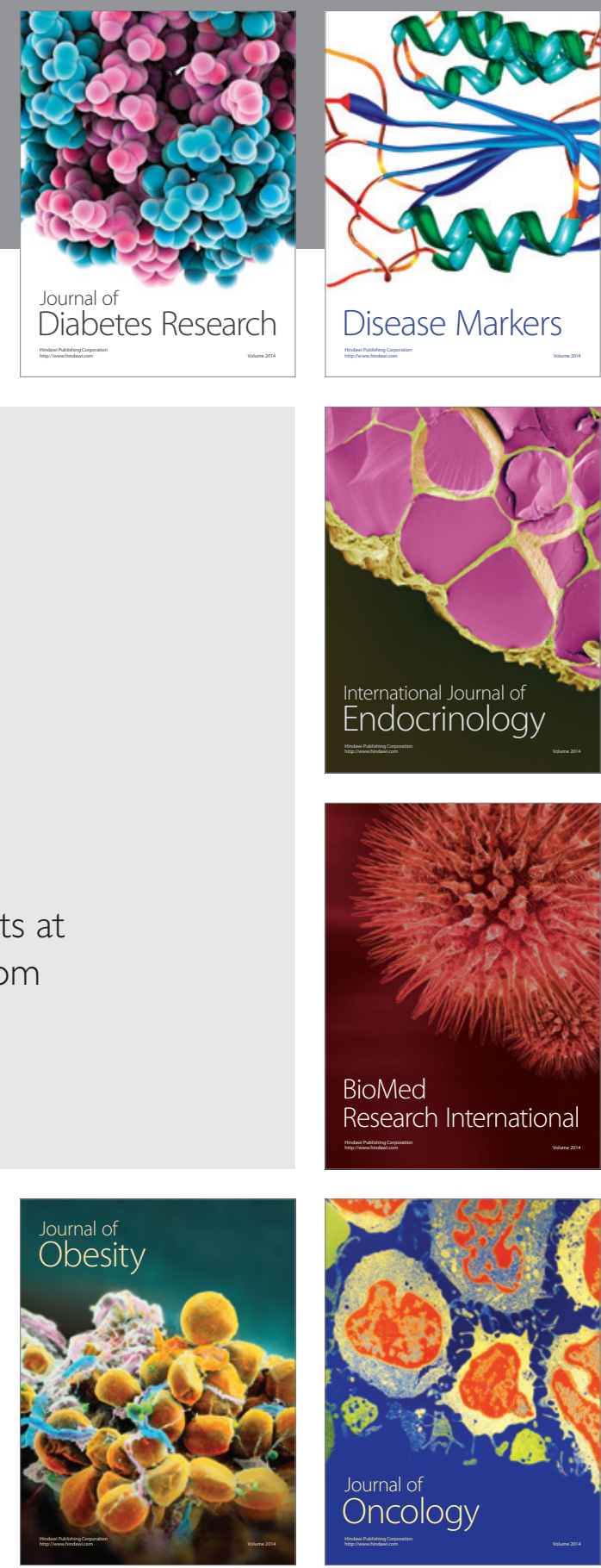

Disease Markers
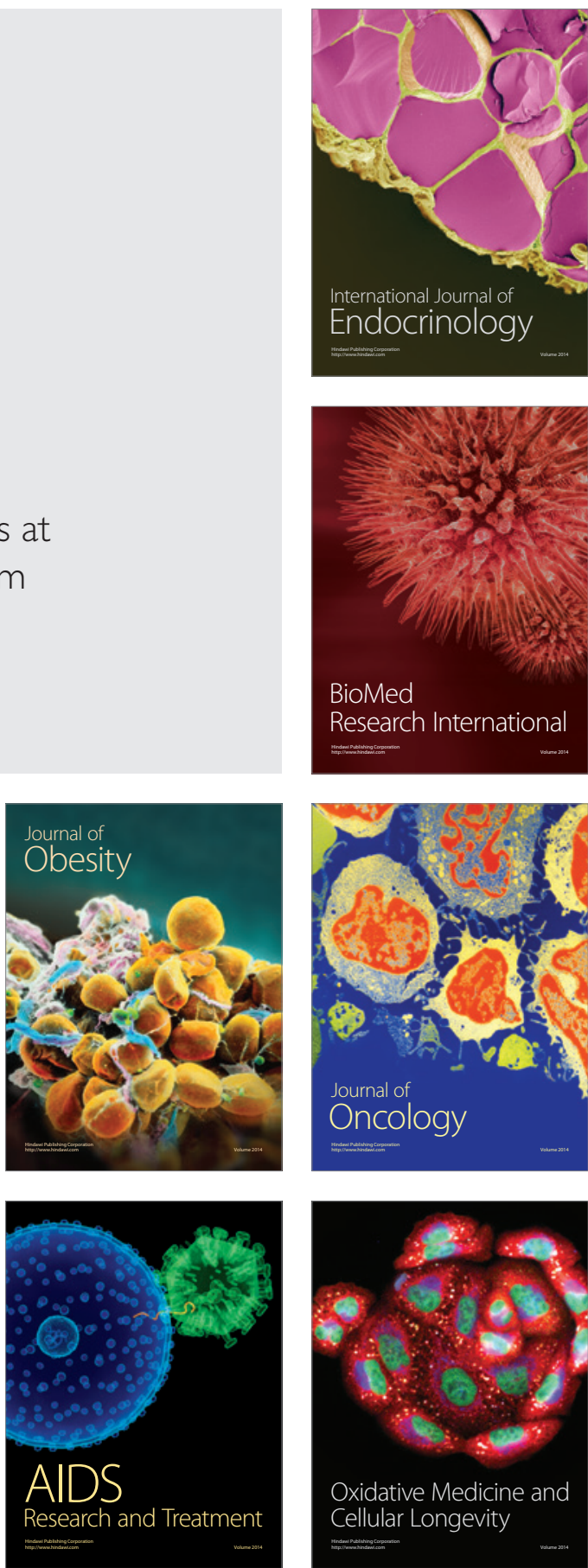